\title{
Modeling and Experiments of Severe Slugging in a Riser System
}

\author{
Lin Wang, ${ }^{1,2}$ Yuxing Li, ${ }^{1,2}$ Chang Liu, ${ }^{1,2}$ Qihui Hu, ${ }^{1,2}$ Yating Wang, ${ }^{3}$ and Quan Wang ${ }^{1,2}$ \\ ${ }^{1}$ College of Pipeline and Civil Engineering, China University of Petroleum, Qingdao 266580, China \\ ${ }^{2}$ Shandong Provincial Key Laboratory of Oil \& Gas Storage and Transportation Safety, Qingdao 266580, China \\ ${ }^{3}$ CCTEG Chongqing Engineering Co., Ltd., Chongqing 400016, China
}

Correspondence should be addressed to Yuxing Li; liyx@upc.edu.cn

Received 23 October 2015; Revised 10 January 2016; Accepted 2 February 2016

Academic Editor: Eleonora Bottani

Copyright (C) 2016 Lin Wang et al. This is an open access article distributed under the Creative Commons Attribution License, which permits unrestricted use, distribution, and reproduction in any medium, provided the original work is properly cited.

\begin{abstract}
A transient mathematical model based on continuity equations for liquid and gas phases, with a momentum equation for the mixture, was developed, and numerical solutions and simulations corresponding to severe slugging in pipeline-riser system were presented, and the results were compared with the experimental data to verify the mathematical model. In numerical solutions, backward Euler schemes were adopted as predictors and trapezoidal methods were used as correctors. Variable time steps were employed for higher computational efficiency and accuracy in the integration. Experiments of severe slugging characteristics were performed, and the simulation results of the cycle periods and bottom pressure were compared with experimental values. Finally, the calculation results of detailed characteristics were analyzed thoroughly. The results show that the developed mathematical model can accurately predict the cycle time and the detailed characteristics of severe slugging. Under the experimental conditions, the liquid slug length can reach 1.6 times the height of the riser, and the maximum instantaneous gas velocity of outlet is 50 times the inlet gas velocity, and the maximum instantaneous liquid velocity of outlet is 28 times the inlet liquid velocity, having important implications for the hazard assessment of severe slugging.
\end{abstract}

\section{Introduction}

In the offshore and deep water oil and gas development, multiphase transportation is more economic as a transportation way. The mixture of oil and gas is transported through the hilly terrain subsea pipeline and the riser to the offshore production platform for oil, gas, and water processing [1]. Severe slug flow occurs at low gas and liquid flow rates, with the downward inclined pipe in stratified flow, and is characterized by the generation of liquid slugs at the base of the riser ranging in length from one to several riser pipe heights. The process of severe slugging in a riser system was considered as a cycle consisting of four steps [2]: (1) slug formation; (2) slug movement out of the riser; (3) blowout; and (4) liquid fallback. The pressure and the instantaneous velocities of gas and liquid flow in the riser system oscillate violently, which may shock the downstream equipment and induce damage such as severe vibration of the riser system and equipment. Therefore, it is essential to simulate the detailed characteristics of severe slugging accurately for the hazard assessment of severe slugging.

Since the severe slugging induced problems were identified by Yocum [3], a great deal of theoretical exploration and experimental studies on severe slugging were developed. In [2], an experiment was carried out to study the characteristics of severe slugging, and a simplified model was presented for simulating the severe slugging [4]. Boe [5] and Jansen et al. [6] presented, respectively, flow regime maps for predicting the severe slug flow regimes, where the boundaries were determined analytically. Huawei [7] studied the characteristics of severe slugging in pipeline-riser system and catenary riser system by detailed laboratory experiment and developed a mathematical model for severe slugging. Zhang et al. [8] set up a one-dimensional quasi-equilibrium simplified calculation model for the unsteady flow in the Ltype riser system, which ignores the effects of friction and acceleration. Baliño et al. $[9,10]$ presented a mathematical model considering continuity equations for liquid and gas 
phases, with a simplified momentum equation for the mixture, neglecting inertia, and considering inertia, respectively, and simulated the transient characteristics of severe slugging. A computational fluid dynamics (CFD) method is proposed for numerically simulating the gas-liquid severe slugging in a pipeline-riser system. Gao et al. [11, 12] implemented 2D numerical simulations of severe slugging by using a CFD software FLUENT. Araújo et al. [13] studied the dynamics of individual and a pair of Taylor bubbles rising in vertical columns of stagnant and cocurrent liquids numerically using the volume of fluid (VOF) methodology implemented in the commercial code ANSYS FLUENT. Li et al. [14] developed a transient model using OLGA to study the dynamic behavior of severe slugging in a pipeline-riser system and compared the simulation results with the experimental data. Xing et al. $[15,16]$ carried out 2D CFD simulations for severe slugging and attempted to develop a 3D-1D coupling simulation, that is, STAR-OLGA coupling, for mitigating hydrodynamic slug flows with a wave pipe, where the 1D simulation for the entire pipeline coupled with the $3 \mathrm{D}$ simulation of the partial flow field was implemented to control the scale of calculation. Looking through current literatures, numerical simulation methods are mainly divided into two categories: (1) numerical simulation of the whole flow field based on CFD; (2) simplified one-dimensional transient model. The former method's advantage is that the detailed characteristic parameters of flow field and the liquid-gas interfaces can be described precisely. However, this method is computationally expensive and difficultly simulates the full-scale of the physical phenomena, so it is difficult to apply this method effectively. The simplified one-dimensional transient model is not only efficient in computation but also more accurate when empirical correlations and experiential parameters are introduced appropriately, and then this method can simulate the engineering scales of multiphase transportation.

In this paper, a modified mathematical model is developed for the severe slugging flow in risers; the continuity equations and momentum equations are described as a series of differential equations for the enhancement of suitability. The numerical integration methods for the mathematical model are presented in detail. The simulation of the liquid fallback is added to improve the accuracy of simulations of the flowing characteristics and cycle period of severe slugging.

\section{The Development of the Mathematical Model}

The hybrid riser facility which consists of a downward inclined pipeline and a riser was built up to simulate the riser system (Figure 1). Liquid and gas flow in the downward inclined pipeline simultaneously and move out at the top of the riser.

A transient model based on continuity equations for liquid and gas phases, with a momentum equation for the mixture, is developed to calculate the characteristic parameters including pressure, position of slug front and tail, void fraction, and flow velocities of gas and liquid.

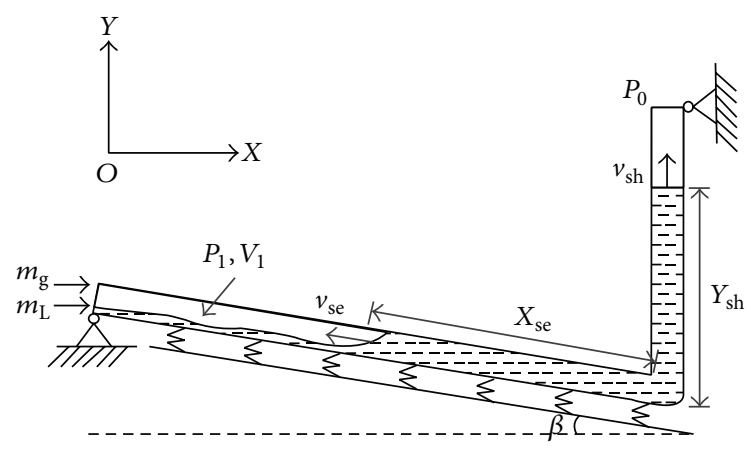

FIGURE 1: Schematic view of the riser system.

The model considers one-dimensional flow in the riser system. The liquid phase is assumed to be incompressible, while the gas phase is considered as an ideal gas. Both phases flow in isothermal conditions. The flow pattern in the downward inclined pipeline is assumed to be stratified, and the liquid holdup along the pipeline is constant. A cycle of severe slugging can be described as taking place according to the following stages.

2.1. Stage 1: Slug Formation; Stage 2: Discharge out of the Riser. In the stage of slug formation, both gas and liquid flow in the riser system, and the liquid accumulates at the bottom of the riser and the gas channel is blocked. The liquid continues to flow in and gas already in the riser continues to flow out, and then the slug front (liquid level) rises and pressure at the bottom of the riser increases, compressing the gas in the downward pipeline and creating a liquid accumulation region. As the slug front reaches the top while the gas channel is kept blocked at the bottom, the bottom pressure reaches a maximum value and there is only liquid flowing in and out of the riser, which is the stage of slug discharge out of the riser.

The governing equations are developed based on continuity equations for the liquid and gas phases and the momentum equation for the mixture. For the stages of slug formation and slug discharge out of the riser, the continuity equation for the liquid is as follows:

$$
v_{\mathrm{Lb}}=\alpha_{\mathrm{P}} v_{\mathrm{se}}+\frac{m_{\mathrm{L} 0}}{\rho_{\mathrm{L}} A},
$$

where $v_{\mathrm{Lb}}$ is the liquid superficial velocity at the bottom of the riser, $\alpha_{\mathrm{P}}$ is the void fraction of the downward pipeline, $v_{\mathrm{se}}$ is the movement velocity of the slug tail, $m_{\mathrm{L} 0}$ is the mass flow rate for the liquid injected in the downward pipeline, $\rho_{\mathrm{L}}$ is the liquid density, and $A$ is the flow passage area.

Using the ideal gas relation $\left(P_{1} V_{1}=M_{\mathrm{g} 0} R T / \mu_{\mathrm{g}}\right.$, where $M_{\mathrm{g} 0}$ is gas mass and $V_{1}$ is gas volume) for the gas in the downward pipeline, differentiating it with time, and considering $P_{1}$ and $X_{\text {se }}$ as a function of time, the gas continuity equation is obtained:

$$
\frac{\mathrm{d} P_{1}}{\mathrm{~d} t}=\frac{-P_{1} \alpha_{\mathrm{P}} v_{\mathrm{se}}+m_{\mathrm{g} 0} R T / \mu_{\mathrm{g}} A}{\left(L+X_{\mathrm{se}}\right) \alpha_{\mathrm{P}}+L e},
$$

where $t$ is time, $P_{1}$ is the pressure of the gas in the downward pipeline, $m_{\mathrm{g} 0}$ is the mass flow rate for the gas injected in 
the downward pipeline, $X_{\text {se }}$ is the displacement of the slug tail relative to the bottom of the riser set as reference point, $L$ is the downward pipeline length, $L e$ is the equivalent pipe length of the buffer vessel, $R$ and $T$ are, respectively, the gas constant and temperature, and $\mu_{\mathrm{g}}$ is the gas molar mass.

The gas pressure $P_{1}$ in the downward pipeline depends on the variations of the positions of the slug front and tail in these stages. Therefore, the momentum equation for the mixture is as follows:

$$
\frac{\mathrm{d} P_{1}}{\mathrm{~d} t}=\frac{\partial P}{\partial Y} \frac{\mathrm{d} Y_{\mathrm{sh}}}{\mathrm{d} t}+\frac{\partial P}{\partial X} \frac{\mathrm{d} X_{\mathrm{se}}}{\mathrm{d} t},
$$

where $P$ is the local static pressure of the fluid, $\partial P / \partial Y$ is the pressure gradient along the riser, $\partial P / \partial X$ is the pressure gradient along the downward inclined pipeline, and $Y_{\mathrm{sh}}$, considered as a function of time, is the displacement of the slug front relative to the bottom of the riser set as reference point.

In (2) and (3)

$$
\frac{\mathrm{d} X_{\mathrm{se}}}{\mathrm{d} t}=v_{\mathrm{se}}
$$

For the stage of slug formation,

$$
\frac{\mathrm{d} Y_{\mathrm{sh}}}{\mathrm{d} t}=v_{\mathrm{Lb}}=v_{\mathrm{sh}}
$$

where $v_{\text {sh }}$ is the movement velocity of the slug front and $v_{\mathrm{Lb}}$ is the liquid superficial velocity at the bottom of the riser.

For the stage of slug discharge out of the riser,

$$
\frac{\mathrm{d} Y_{\mathrm{sh}}}{\mathrm{d} t}=v_{\mathrm{Lb}}=0
$$

In the above equations, there are 4 unknown independent variables $\left(X_{\mathrm{se}}, Y_{\mathrm{sh}}, P_{1}\right.$, and $\left.\alpha_{\mathrm{P}}\right)$ that need to be solved, and the other parameters are known parameters or intermediate variables. However, there are 3 independent equations including (1)-(3). Therefore, another equation should be introduced to make the system of equation closed.

The void fraction of the downward pipeline is calculated from the liquid holdup correlations for inclined two-phase flow [17] which can be calculated by

$$
\begin{aligned}
\alpha_{\mathrm{P}} & =1-\exp \left[\left(-1.3+4.8 \sin \beta+4.2 \sin ^{2} \beta+56.3 N_{\mathrm{L}}^{2}\right)\right. \\
& \left.\cdot \frac{N_{\mathrm{gw}}^{0.08}}{N_{\mathrm{Lw}}^{0.505}}\right],
\end{aligned}
$$

where $N_{\mathrm{gw}}$ is gas velocity number, $N_{\mathrm{Lw}}$ is liquid velocity number, and $N_{\mathrm{L}}$ is liquid viscosity number calculated as follows:

$$
\begin{aligned}
& N_{\mathrm{gw}}=v_{\mathrm{sg}}\left(\frac{\rho_{\mathrm{L}}}{g \sigma}\right)^{0.25}, \\
& N_{\mathrm{LW}}=v_{\mathrm{sL}}\left(\frac{\rho_{\mathrm{L}}}{g \sigma}\right)^{0.25}, \\
& N_{\mathrm{L}}=\eta_{\mathrm{L}}\left(\frac{g}{\rho_{\mathrm{L}} \sigma^{3}}\right)^{0.25},
\end{aligned}
$$

where $\eta_{\mathrm{L}}$ is dynamic viscosity of liquid, $\sigma$ is surface tension, and $\beta$ is pipe inclination angle from horizontal.

2.2. Stage 3: Blowout. As the gas phase penetrates into the riser, the column becomes lighter, decreasing the pressure, and then the gas expands to rise and push the liquid slug to accelerate. The governing equations for the stage of blowout are presented as follows.

The continuity equation for the liquid is

$$
\frac{\mathrm{d}\left(Y_{\mathrm{se}} \alpha_{\mathrm{r}}\right)}{\mathrm{d} t}+v_{\mathrm{sL}}-v_{\mathrm{Lt}}=0 .
$$

The continuity equation for the gas is

$$
\frac{\mathrm{d} P_{1}}{\mathrm{~d} t}=\frac{-P_{1} v_{\mathrm{gb}}+m_{\mathrm{g} 0} R T / \mu_{\mathrm{g}} A}{L \alpha_{\mathrm{P}}+L e} .
$$

The momentum equation for the mixture is

$$
\begin{aligned}
& \frac{\partial P}{\partial Y}+\rho_{\mathrm{L}} \frac{\partial\left[\left(1-\alpha_{\mathrm{r}}\right)\left(v_{\mathrm{sg}}+v_{\mathrm{sL}}\right)\right]}{\partial t}+\rho_{\mathrm{L}} g\left(1-\alpha_{\mathrm{r}}\right)+\frac{4 \tau_{\mathrm{w}}}{D} \\
& \quad=0 .
\end{aligned}
$$

In (9)

$$
\frac{\mathrm{d} Y_{\mathrm{se}}}{\mathrm{d} t}=v_{\mathrm{se}},
$$

where $v_{\mathrm{sg}}=v_{\mathrm{gb}}, \alpha_{\mathrm{r}}=v_{\mathrm{gb}} / v_{\mathrm{se}}, v_{\mathrm{Lb}}=m_{\mathrm{L} 0} / \rho_{\mathrm{L}} A, Y_{\mathrm{se}}$ and $v_{\mathrm{se}}$ are, respectively, the position and the movement speed of the slug tail in the riser, $v_{\mathrm{Lt}}$ is the liquid superficial velocity at the top of the riser, and $v_{\text {se }}$ can be calculated by Nicklin et al. [18] as follows:

$$
v_{\text {se }}=C_{0}\left(v_{\mathrm{sg}}+v_{\mathrm{sL}}\right)+V_{0}
$$

where $v_{\text {sg }}$ and $v_{\mathrm{sL}}$ are the local gas superficial velocity and the local liquid superficial velocity, respectively.

In the above equations, the independent equations are (9)-(11) and (13), and the unknown variables are $P, Y_{\mathrm{se}}, v_{\mathrm{Lt}}$, and $v_{\mathrm{gb}}$. The system of equation is closed.

When gas reaches the top of the riser, two-phase gasliquid flow in the riser exhibits a chaotic flow pattern consisting of Taylor bubbles and liquid slug is identified as churn flow by Tengesdal et al. [19] and the gas velocity is calculated using Tengesdal et al. correlations:

$$
v_{\mathrm{g}}=C_{0} v_{\mathrm{m}}+v_{\mathrm{D}}
$$

2.3. Stage 4: Liquid Fallback. The gas and liquid blow out of the riser until the gas flow rate becomes too low to drive the liquid rising in the riser, and then the liquid falls down to the bottom of the riser. The liquid fallback can be described as follows:

$$
\begin{aligned}
\frac{\mathrm{d} v_{\mathrm{fd}}}{\mathrm{d} t} & =g-\lambda_{\mathrm{d}}, \\
V_{\mathrm{f}} & =\int_{0}^{H}\left(1-\alpha_{\mathrm{r}}\right) A \mathrm{~d} Y, \\
P_{\mathrm{f}} & =\rho_{\mathrm{L}} g \frac{V_{\mathrm{f}}}{A},
\end{aligned}
$$


TABLE 1: Parameters of the riser system and severe slugging flow.

\begin{tabular}{lc}
\hline Parameter & Value \& unit \\
\hline Pipe OD & $63 \mathrm{~mm}$ \\
Wall thickness & $5.8 \mathrm{~mm}$ \\
Riser height & $3.5 \mathrm{~m}$ \\
Pipeline length & $12 \mathrm{~m}$ \\
Inclination angle & $4^{\circ}$ \\
Liquid density & $1000 \mathrm{~kg} \cdot \mathrm{m}^{-3}$ \\
Liquid viscosity & $0.001 \mathrm{~Pa} \cdot \mathrm{s}$ \\
Surface tension & $7.28 \times 10^{-2} \mathrm{~N} \cdot \mathrm{m}^{-1}$ \\
Gas molar mass & $29 \mathrm{~g} \cdot \mathrm{mol}^{-1}$ \\
Gas constant & $8.31 \mathrm{~J} \cdot \mathrm{mol}^{-1} \cdot \mathrm{K}^{-1}$ \\
\hline
\end{tabular}

where $v_{\mathrm{fd}}, \lambda_{\mathrm{d}}$, and $V_{\mathrm{f}}$ are the falling down velocity, friction coefficient, and volume of the liquid, respectively, $P_{\mathrm{f}}$ is pressure at the bottom of the riser caused by the falling liquid, and $g$ is gravitational acceleration.

After the liquid falls down at the bottom of the riser, the liquid flows back into the downward pipeline because of the potential energy of the falling liquid. The process can be described as follows:

$$
\frac{\mathrm{d} v_{\mathrm{fb}}}{\mathrm{d} t}=g-\lambda_{\mathrm{b}}
$$

where $v_{\mathrm{fb}}$ and $\lambda_{\mathrm{b}}$ are, respectively, the flowing back velocity and friction coefficient of the liquid.

\section{Boundary and Initial Conditions}

The boundary conditions of inlet are the liquid mass flow rate and the gas mass flow rate which are constants (Table 1), and the temperature is $300 \mathrm{~K}$. The boundary condition of outlet is the pressure at the top of the riser:

$$
P\left(Y=H_{\mathrm{r}}, t\right)=P_{0},
$$

where $P_{0}$ is approximately equal to the atmospheric pressure $(101.325 \mathrm{kPa})$.

The initial conditions including the positions and the velocities of slug tail and front are given as follows:

$$
\begin{aligned}
X_{\text {se }}(t=0) & =-1.4, \\
Y_{\text {sh }}(t=0) & =0, \\
v_{\text {se }}(t=0) & =0, \\
v_{\text {sh }}(t=0) & =0 .
\end{aligned}
$$

The pressure and superficial velocities at the bottom of the riser are continuous:

$$
\begin{gathered}
P(X=0, t)=P(Y=0, t), \\
v_{\mathrm{sg}}(X=0, t)=v_{\mathrm{sg}}(Y=0, t)=v_{\mathrm{gb}}(t), \\
v_{\mathrm{sL}}(X=0, t)=v_{\mathrm{sL}}(Y=0, t)=v_{\mathrm{Lb}}(t) .
\end{gathered}
$$

\section{Discretization of the Model}

4.1. Slug Formation and Discharge out of the Riser. The equations are discretized using explicit schemes for the stages of the slug formation and discharge out of the riser. The Euler scheme for (2) is

$$
\begin{aligned}
& P_{1}^{K+1} \\
& =\frac{P_{1}^{K}+\left(m_{\mathrm{g} 0} R T / \mu_{\mathrm{g}} A\right)\left(\Delta t^{K} /\left(\left(L+X_{\mathrm{se}}^{K}\right) \alpha_{\mathrm{P}}+L e\right)\right)}{1+\left(\alpha_{\mathrm{p}} v_{\mathrm{se}}^{K} \Delta t^{K} /\left(\left(L+X_{\mathrm{se}}^{K}\right) \alpha_{\mathrm{P}}+L e\right)\right)} .
\end{aligned}
$$

is

Combining (1) into (3), the discretization scheme for (3)

$$
P_{1}^{K+1}=P_{1}^{K}+\rho_{\mathrm{L}} g\left(\frac{m_{\mathrm{L} 0}}{\rho_{\mathrm{L}} A}+\alpha_{\mathrm{P}} v_{\mathrm{se}}^{K}+v_{\mathrm{se}}^{K} \sin |\beta|\right) \Delta t^{K} .
$$

The discretization scheme for (4) is

$$
X_{\mathrm{se}}^{K+1}=X_{\mathrm{se}}^{K}+v_{\mathrm{se}}^{K} \Delta t^{K},
$$

where $\Delta t^{K}\left(=t^{K+1}-t^{K}\right)$ is the time step and the superscripts $K$ and $K+1$ denote variables correspondingly at times. In particular, $v_{\mathrm{se}}^{K}$ is defined as the average velocity of the slug tail in $\Delta t^{K}$. Therefore, the difference schemes are unconditionally convergent to the time step, and larger time step can be adopted to improve the calculation efficiency in the stages of the slug formation and movement out of the riser.

4.2. Blowout. In the stage of blowing out, because of the existence of the fluid acceleration term, the time step should be smaller in the integration process for higher calculation accuracy and the trapezoidal methods are used to correct the predicted values. The equations are discretized using implicit schemes with a predictor-corrector method for the stages of blowout. For (9)-(12),

$$
\begin{aligned}
P_{1}^{K+1}= & \frac{P_{1}^{K}+\left(m_{\mathrm{g} 0} R T / \mu_{\mathrm{g}} A\right)\left(\Delta t^{K} /\left(L \alpha_{\mathrm{P}}+L e\right)\right)}{1+\left(v_{\mathrm{gb}}^{K+1} \Delta t^{K} /\left(L \alpha_{\mathrm{P}}+L e\right)\right)}, \\
P_{N+1}^{K+1}= & P_{N}^{K+1}-\Delta Y_{N}\left[\rho_{\mathrm{L}}\left(1-\alpha^{K+1}\right)+\frac{4 \tau_{\mathrm{w}}}{D}\right] \\
& +\Delta Y_{N} \rho_{\mathrm{L}} \frac{v_{\mathrm{m}}^{K+1}\left(\alpha^{K+1}-1\right)-v_{\mathrm{m}}^{K}\left(\alpha^{K}-1\right)}{\Delta t^{K}} .
\end{aligned}
$$

The position of the slug tail can be predicted by a backward Euler method and the prediction formula is

$$
{ }^{(i)} Y_{\mathrm{se}}^{K+1}=Y_{\mathrm{se}}^{K}+v_{\mathrm{se}}^{K+1} \Delta t^{K} .
$$

The correction formula with the trapezoidal method is

$$
{ }^{(i+1)} Y_{\mathrm{se}}^{K+1}=Y_{\mathrm{se}}^{K}+\left(v_{\mathrm{se}}^{K}+{ }^{(i)} v_{\mathrm{se}}^{K+1}\right) \frac{\Delta t^{K}}{2},
$$

where $\Delta Y_{N}$ is the space interval, subscript $N$ indicates the number of the space intervals, ${ }^{(i+1)} Y_{\mathrm{se}}^{K+1}$ is the correction value of $Y_{\mathrm{se}}^{K+1}$, and $i+1$ is the number of correction iterations. For instance, it is the 1st correction when $i=0$ and $i+1=1$ and the 2 nd correction when $i=1$ and $i+1=2$. 


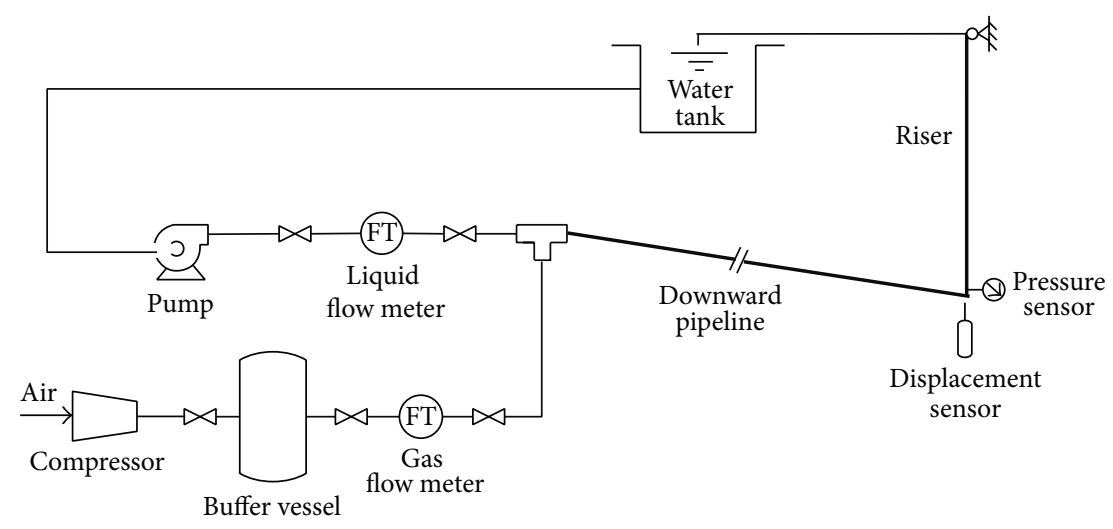

FIGURE 2: Schematic diagram of experimental facility of riser system.

4.3. Fallback. The analytic solutions of characteristic parameters of this stage can be distinctly solved for (15)-(16).

\section{Simulation Results and Discussion}

5.1. Experimental Verification. Figure 2 shows a schematic of the riser test facility with the instrumentation. The test loop consists of a $35 \mathrm{~m}$ long horizontal pipeline and a $12 \mathrm{~m}$ long, $51.4 \mathrm{~mm}$ diameter pipeline which is inclined to $-4^{\circ}$ from the horizontal, connected to a $3.5 \mathrm{~m}$ high vertical riser.

The water is supplied from two $0.5 \mathrm{~m}^{3}$ storage tanks, also acting as receivers for the water returning from the test loop. Water is delivered into the test loop using two pumps which can be operated either individually or in series. Each of the pumps has $12.5 \mathrm{~m}^{3} / \mathrm{h}$ capacity and maximum discharge pressure of $0.5 \mathrm{MPa}$. Air is supplied from a reciprocating compressor with a maximum capacity of $61.5 \mathrm{~L} / \mathrm{s}$ at $1.25 \mathrm{MPa}$. The compressor supplies air into a $2 \mathrm{~m}^{3}$ buffer vessel which acts as an air receiver and smoothes any pressure fluctuations from the compressor. Gas flow rates are controlled using a needle valve downstream of the air receiver. The detailed parameters of the experimental facility and the gas-liquid two-phase flow are shown in Table 1.

The characteristic parameters of the severe slugging under different inlet conditions were measured in the laboratory, and the characteristics were simulated using the mathematical method described above. The experimental and the theoretical results are summarized in Table 2. The experimental results for the cycle time under different experimental conditions are presented, and the theoretical results for these variables and the relative errors are also given in Table 2. It shows that the simulation results agree with the experimental results essentially. However, the error will be larger when the gas superficial velocity increases, which is because the flow regime gradually deviates from the typical severe slugging and cannot be described by the mathematical model accurately when the gas flow rate increases. Otherwise, the measurement error can cause the bigger simulation error.

Original pressure signals measured in experiment were denoised using wavelet analysis method, and the denoised signals were compared with the simulation results. As shown
TABLE 2: Comparison between experimental and theoretical results.

\begin{tabular}{|c|c|c|c|c|}
\hline \multicolumn{2}{|c|}{ Inlet conditions } & \multirow{2}{*}{$\begin{array}{l}\text { Experimental } \\
\text { cycle time (s) }\end{array}$} & \multirow{2}{*}{$\begin{array}{l}\text { Theoretical } \\
\text { cycle time (s) }\end{array}$} & \multirow{2}{*}{$\begin{array}{c}\text { Error } \\
(\%)\end{array}$} \\
\hline$v_{\mathrm{sg}}(\mathrm{m} / \mathrm{s})$ & $v_{\mathrm{sL}}(\mathrm{m} / \mathrm{s})$ & & & \\
\hline 0.0407 & 0.240 & 70 & 81 & 15.7 \\
\hline 0.0696 & 0.207 & 60 & 57 & -5.0 \\
\hline 0.0830 & 0.215 & 53 & 48 & -9.4 \\
\hline 0.1446 & 0.324 & 25 & 26 & 4.0 \\
\hline 0.2060 & 0.379 & 25 & 22 & -12.0 \\
\hline 0.2060 & 0.423 & 15 & 17 & 13.3 \\
\hline 0.250 & 0.402 & 15 & 18 & 20.0 \\
\hline 0.2819 & 0.423 & 16 & 17 & 6.3 \\
\hline 0.2956 & 0.339 & 25 & 18 & -28.0 \\
\hline 0.3791 & 0.152 & 23 & 21 & -8.7 \\
\hline 0.3823 & 0.369 & 18 & 16 & -11.1 \\
\hline 0.4311 & 0.121 & 52 & 32 & -38.5 \\
\hline
\end{tabular}

in Figure 3, the original pressure signal under the inlet condition $\left(v_{\mathrm{sg}}=0.083 \mathrm{~m} / \mathrm{s}\right.$ and $\left.v_{\mathrm{sL}}=0.215 \mathrm{~m} / \mathrm{s}\right)$ is discomposed to get wavelet of various scales and the a 8 component is reconstructed as the denoised signal. Figure 3 shows the comparison of the original pressure signal and the denoised signal.

Figure 4 shows the different stages in the pressure history at the bottom of the riser calculated from the transient model against the experimental data under laboratory conditions. The four stages of the severe slugging are marked in the figure, and the time span of each stage and the cycle period are obtained distinctly. Agreement seems to be good, although the blowout time (stage 3) calculated by mathematical model is slightly shorter than the experimental value, which is because the predicted value of the friction coefficient in stage 3 is slightly smaller. The simulation results and the experimental results of the falling back (stage 4) are in agreement, but the details are difficult to match because the mathematical model cannot describe the gas-liquid exchange process when the liquid flows back into the downward inclined pipeline. 

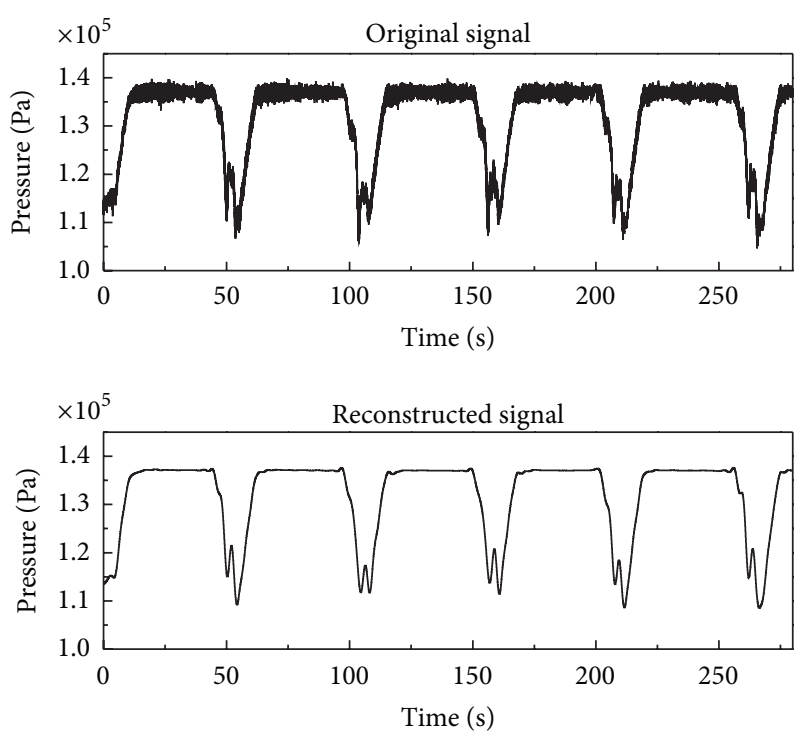

Figure 3: Denoising with wavelet analysis method.

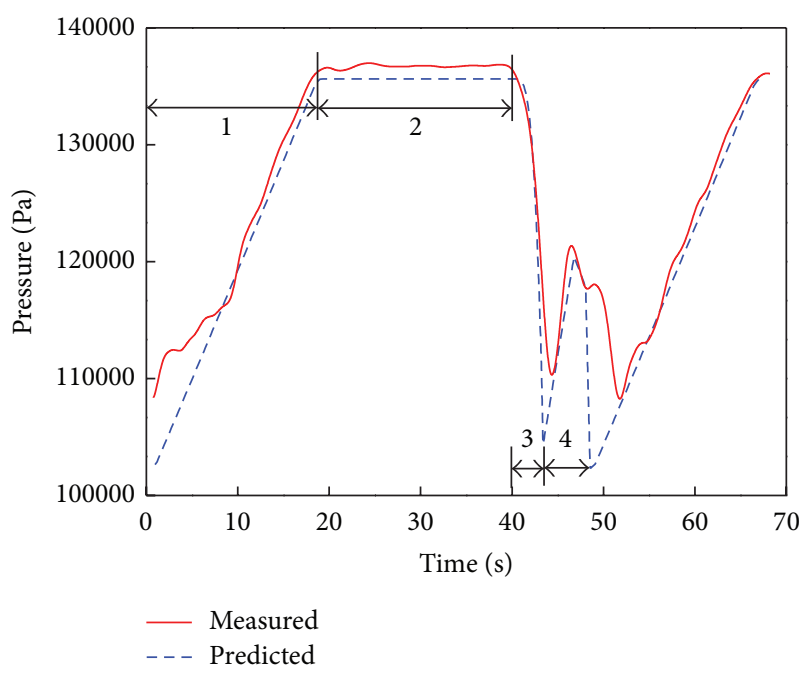

FIgURE 4: Comparison of simulation and experiment results of the pressure at the bottom of the riser $\left(v_{\mathrm{sg}}=0.083 \mathrm{~m} / \mathrm{s}\right.$ and $v_{\mathrm{sL}}=$ $0.215 \mathrm{~m} / \mathrm{s}$ ).

5.2. Transient Characteristics of Severe Slugging. The following figures show the transient simulations corresponding to different variables necessary to characterize the severe slugging: the positions of the slug front and the slug tail (Figure 5(a)), void fraction of the two-phase flow (Figure 5(b)) in the riser, gas superficial velocity (Figure 5(c)) and liquid superficial velocity (Figure 5(d)) at the bottom of the riser, and gas superficial velocity (Figure $5(\mathrm{e})$ ) and liquid superficial velocity (Figure 5(f)) at the top of the riser.

Figure 5(a) shows the time history of the positions of the slug front and tail of severe slugging. The slug length can be calculated by the difference of the positions of the slug front and tail, and the maximum of slug length can reach $5.5 \mathrm{~m}$.
The void fraction of the two-phase flow (Figure 5(b)) in the riser reaches the maximum (0.95) and the minimum $(0.23)$ in the stage of blowing out while the riser is full of liquid during other stages. The gas superficial velocity (Figure 5(c)) at the bottom of the riser reaches the maximum $(4 \mathrm{~m} / \mathrm{s})$ in the stage of blowing out. The liquid superficial velocity (Figure 5(d)) at the bottom of the riser keeps a stable level between 0.19 and $0.21 \mathrm{~m} / \mathrm{s}$.

The gas superficial velocity (Figure 5(e)) of the blowing flow reaches the maximum $(4.0 \mathrm{~m} / \mathrm{s})$, and the liquid superficial velocity (Figure 5(f)) of the blowing flow reaches the maximum $(6.0 \mathrm{~m} / \mathrm{s})$ at the top of the riser in the stage of blowing out.

\section{Conclusions}

A transient mathematical model for severe slugging, based on continuity equations and momentum equation, was developed to simulate the characteristics of severe slugging. The laboratory experiment was implemented and the experimental results were compared with the simulation results to verify the accuracy of the mathematical model. The conclusions of the study are the following:

(1) The process of severe slugging in the riser system is considered to consist of four stages, and based on this, a transient mathematical model is developed, and the numerical integration methods for the mathematical model are developed.

(2) The transient mathematical model has high computing efficiency. Moreover, the model is more accurate for calculating the transient parameters of the severe slugging when empirical correlations and experiential parameters are introduced appropriately.

(3) The characteristic parameters of the severe slugging under different inlet conditions were measured in the laboratory, and the experimental results for the cycle time were compared with the simulation results for these variables and the relative errors are also given. It shows that the simulation results agree with the experimental results essentially; however, the deviation between the experimental result and the simulation result will be larger when the gas superficial velocity increases.

(4) The liquid slug length can reach 1.6 times the height of the riser, and the maximum of the instantaneous gas velocity of outlet is 50 times the inlet gas velocity, and the maximum instantaneous liquid velocity of outlet is 28 times the inlet liquid velocity under the laboratory conditions, which have important implications for the hazard assessment of severe slugging.

\section{Conflict of Interests}

The authors declare that there is no conflict of interests regarding the publication of this paper. 


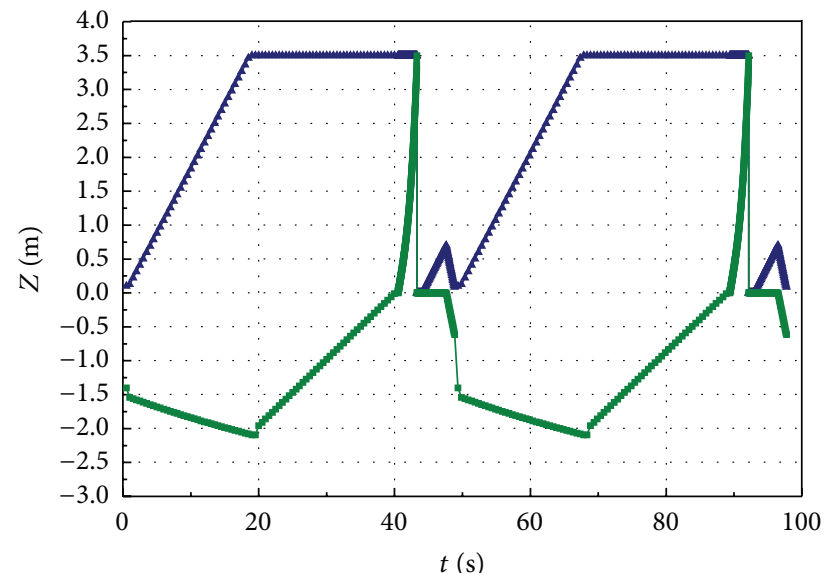

$\rightarrow$ Slug front

$\rightarrow$ Slug tail

(a)

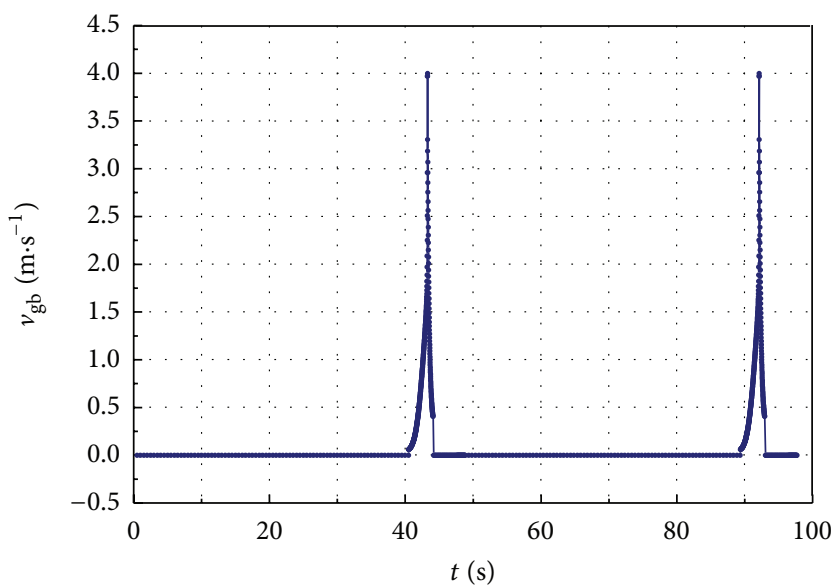

(c)

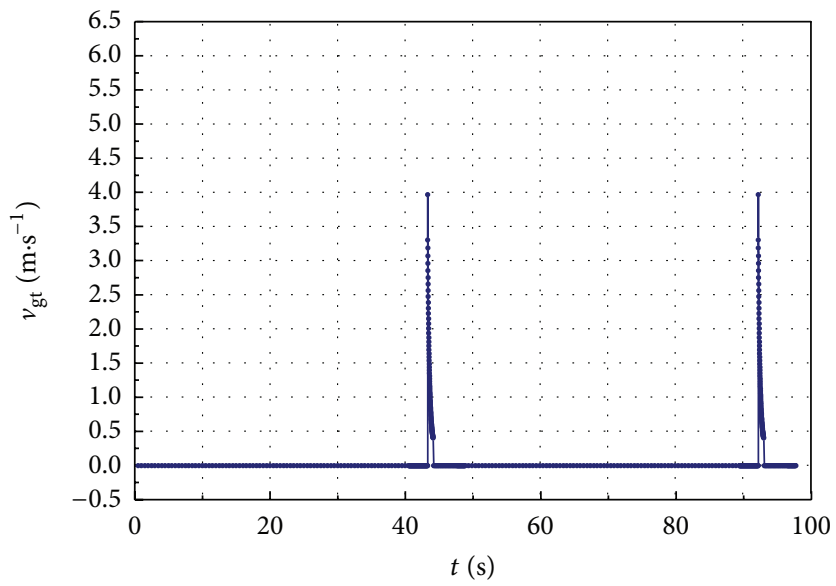

(e)

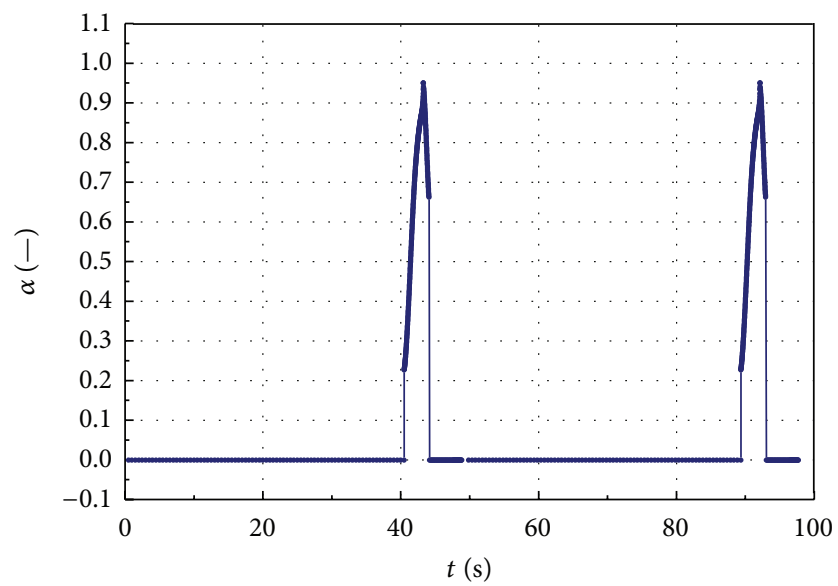

(b)

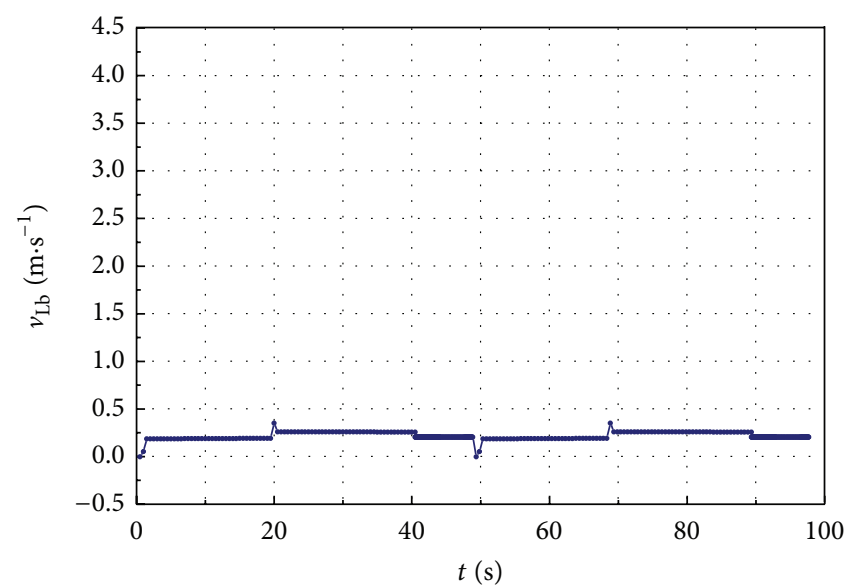

(d)

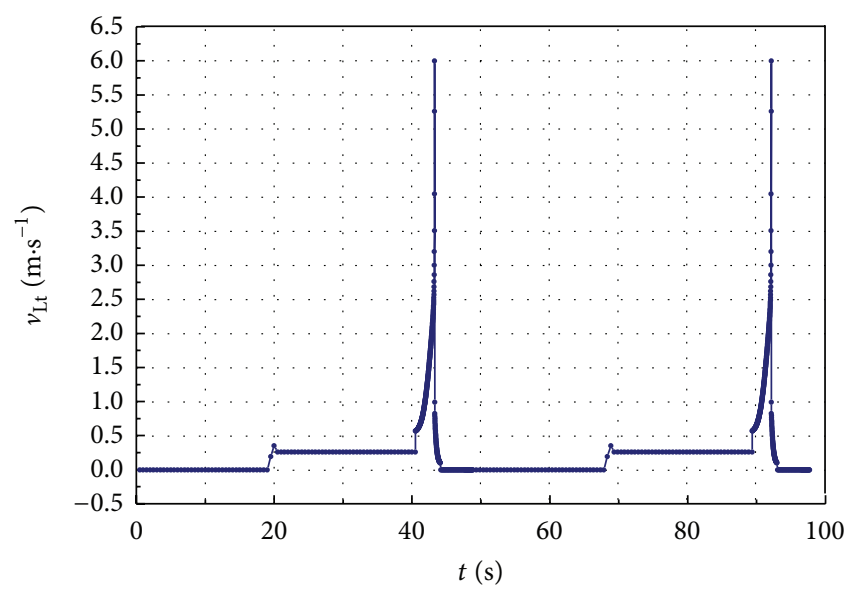

(f)

FIGURE 5: Simulation results of transient flow characteristics of severe slugging $\left(v_{\mathrm{sg}}=0.083 \mathrm{~m} / \mathrm{s}\right.$ and $\left.v_{\mathrm{sL}}=0.215 \mathrm{~m} / \mathrm{s}\right)$. 


\section{Acknowledgment}

For the work described in this paper, the authors would like to express their gratitude for the support from the National Science Fund for Distinguished Young Scholars (no. 51404290).

\section{References}

[1] Y. Li and S. Feng, Oil-Gas-Water Multi-Phase Piping Flow, UPC Press, Dongying, China, 2010.

[2] Z. Schmidt, J. P. Brill, and H. D. Beggs, "Experimental study of severe slugging in a two-phase-flow pipeline-riser pipe system," Society of Petroleum Engineers Journal, vol. 20, no. 5, pp. 407-414, 1980.

[3] B. T. Yocum, "Offshore riser slug flow avoidance: mathematical models for design and optimization," in SPE European Meeting, SPE-4312-MS, Society of Petroleum Engineers, London, UK, April 1973.

[4] Z. Schmidt, D. R. Doty, and K. Dutta-Roy, "Severe slugging in offshore pipeline riser-pipe systems," Society of Petroleum Engineers Journal, vol. 25, no. 1, pp. 27-38, 1985.

[5] A. Boe, Severe Slugging Characteristics, Part 1: Flow Regime for Severe Slugging; Part 2: Point Model Simulation Study, Two Phase Flow, NTH, Trondheim, Norway, 1981.

[6] F. E. Jansen, O. A. Shoham, and Y. Taitel2, "The elimination of severe slugging-experiments and modeling," International Journal of Multiphase Flow, vol. 22, no. 6, pp. 1055-1072, 1996.

[7] M. A. Huawei, Investigation on Severe Slugging Phenomenon and Elimination Methods in Multiphase Riser Pipe System, CUPH, Qingdao, China, 2008.

[8] Q. Zhang, D. Deng, Y. Dong et al., "Simplified calculation model for unsteady flow in marine L-type riser system," Oil \& Gas Storage and Transportation, vol. 33, no. 1, pp. 95-107, 2014.

[9] J. L. Baliño, K. P. Burr, and R. H. Nemoto, "Modeling and simulation of severe slugging in air-water pipeline-riser systems," International Journal of Multiphase Flow, vol. 36, no. 8, pp. 643$660,2010$.

[10] J. L. Baliño, "Modeling and simulation of severe slugging in airwater systems including inertial effects," Journal of Computational Science, vol. 5, no. 3, pp. 482-495, 2014.

[11] S. Gao, Y. You, W. Li et al., "Numerical simulation of the severe slug flow between water-air phases in a declination pipe-riser," Chinese Journal of Theoretical and Applied Mechanics, vol. 43, no. 3, pp. 468-475, 2011.

[12] S. Gao, W. Li, Y.-X. You, and T.-Q. Hu, "Numerical investigation on the gas-liquid severe slugging in a pipeline-riser system," Acta Physica Sinica, vol. 61, no. 10, Article ID 104701, 2012.

[13] J. D. P. Araújo, J. M. Miranda, and J. B. L. M. Campos, "Simulation of slug flow systems under laminar regime: hydrodynamics with individual and a pair of consecutive Taylor bubbles," Journal of Petroleum Science and Engineering, vol. 111, pp. 1-14, 2013.

[14] S. Li, L. Guo, and N. Li, "Transient simulation of severe slugging and riser topside choking," Journal of Engineering Thermophysics, vol. 35, no. 1, pp. 104-108, 2014.

[15] L. Xing, H. Yeung, J. Shen, and Y. Cao, "Numerical study on mitigating severe slugging in pipeline/riser system with wavy pipe," International Journal of Multiphase Flow, vol. 53, pp. 1-10, 2013.
[16] L. Xing, H. Yeung, Y. Geng, Y. Cao, and J. Shen, "Study on hydrodynamic slug flow mitigation with wavy pipe using a 3D1D coupling approach," Computers \& Fluids, vol. 99, pp. 104-115, 2014.

[17] H. Mukherjee and J. P. Brill, "Liquid holdup correlations for inclined two-phase flow," Journal of Petroleum Technology, vol. 35, no. 5, pp. 1003-1008, 1983.

[18] D. J. Nicklin, M. A. Wilkes, and J. F. Davison, "Two-phase flow in vertical tubes," Transactions on Institute of Chemical Engineers, vol. 40, pp. 61-68, 1962.

[19] J. Ø. Tengesdal, A. S. Kaya, and C. Sarica, "Flow-pattern transition and hydrodynamic modeling of churn flow," $S P E$ Journal, vol. 4, no. 4, pp. 342-348, 1999. 


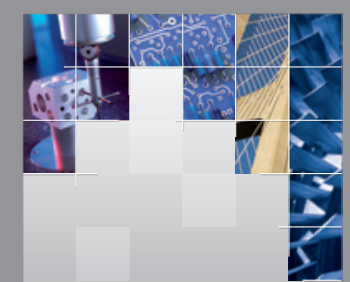

\section{Enfincering}
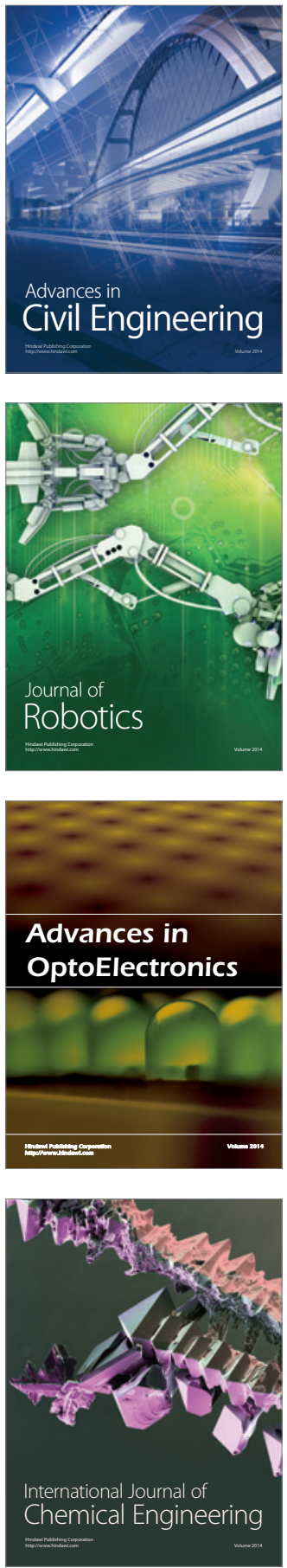

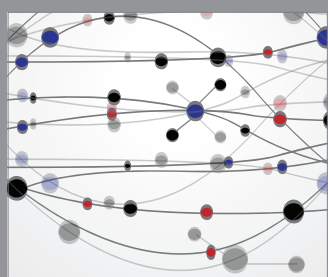

The Scientific World Journal

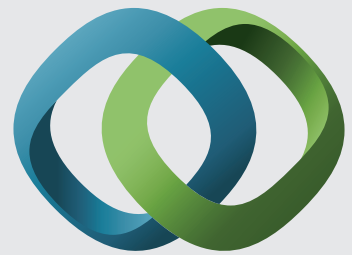

\section{Hindawi}

Submit your manuscripts at

http://www.hindawi.com
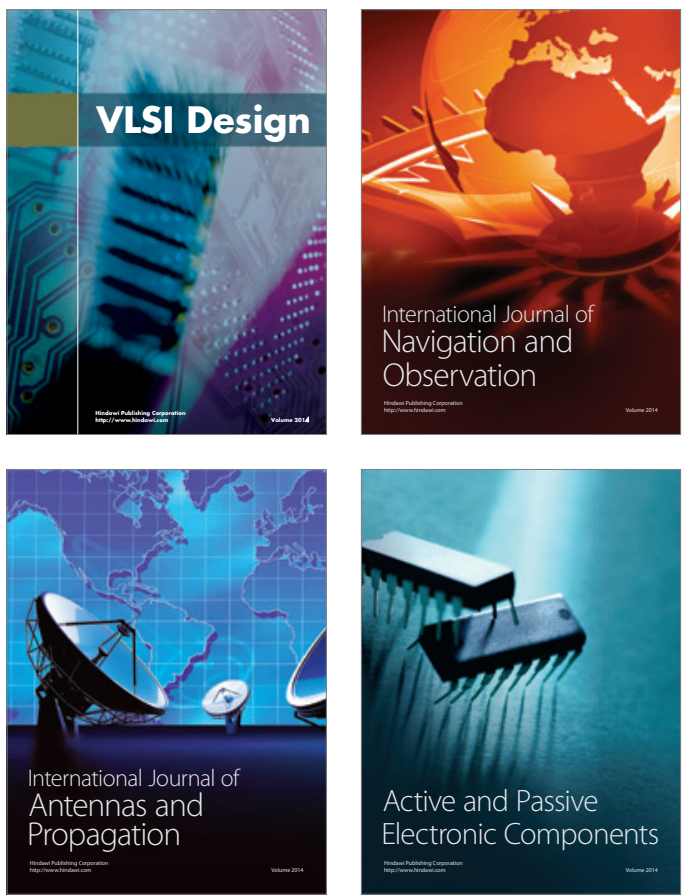
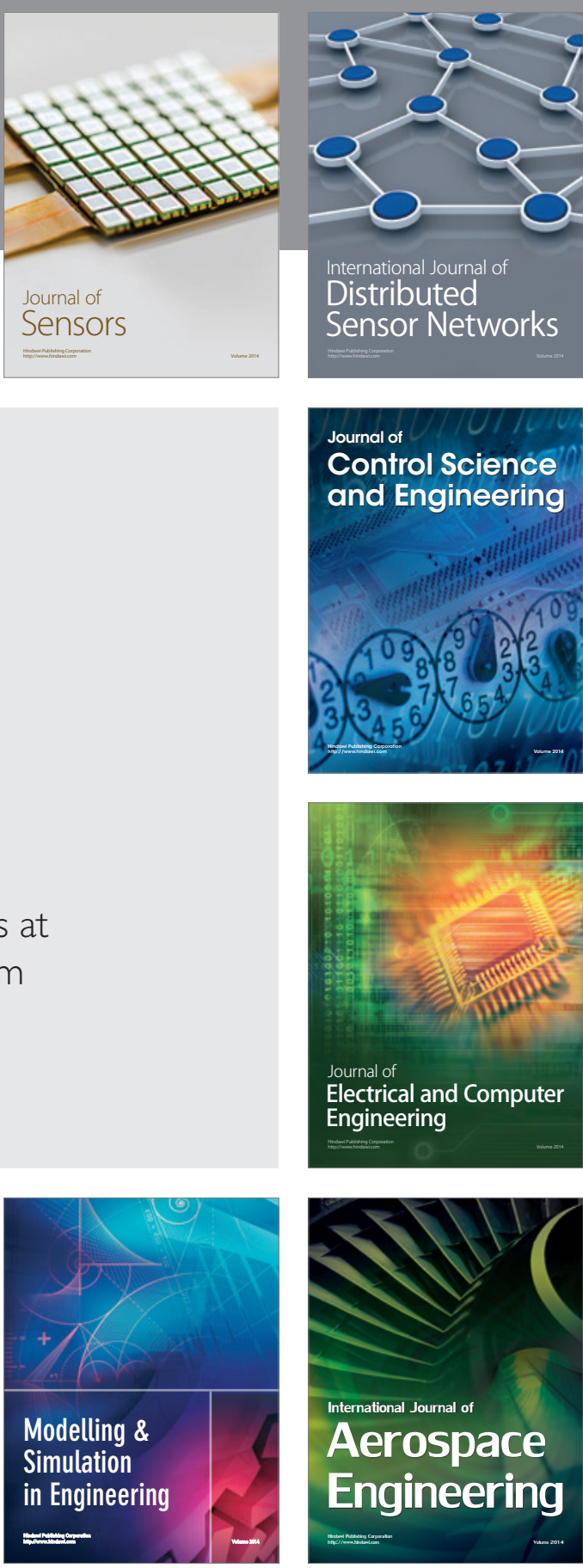

International Journal of

Distributed

Sensor Networks

Journal of

Control Science

and Engineering
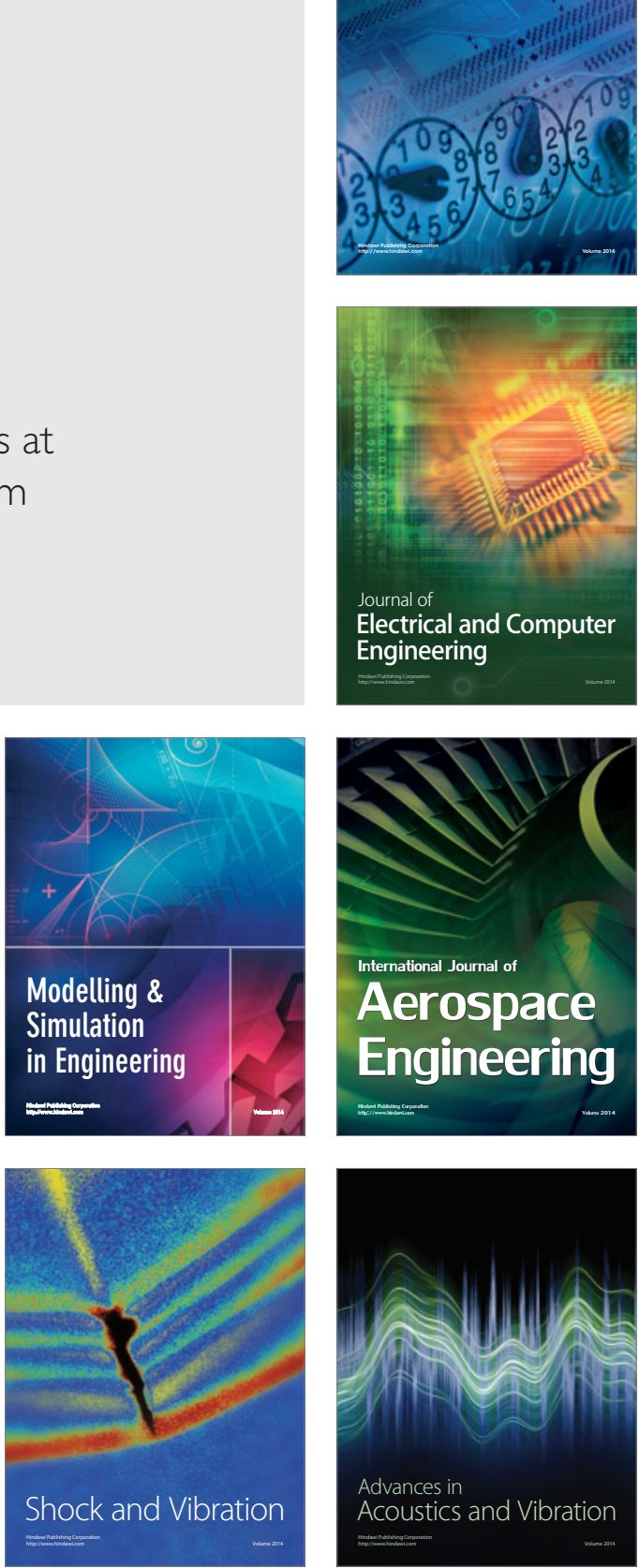